\title{
Corrigendum: Valenced action/inhibition learning in humans is modulated by a genetic variant linked to dopamine D2 receptor expression
}

\author{
Anni Richter ${ }^{1 *}$, Marc Guitart-Masip ${ }^{2,3}$, Adriana Barman ${ }^{1}$, Catherine Libeau 1, \\ Gusalija Behnisch ${ }^{1}$, Sophia Czerney ${ }^{1}$, Denny Schanze ${ }^{4}$, Anne Assmann ${ }^{1}$, \\ Marieke Klein ${ }^{1 \dagger}$, Emrah Düzel ${ }^{5,6,7,8}$, Martin Zenker ${ }^{4}$, Constanze Seidenbecher ${ }^{1,8}$ and \\ Björn H. Schott ${ }^{1,8,9,10}$
}

\begin{abstract}
${ }^{1}$ Department of Neurochemistry and Molecular Biology and Department of Behavioral Neurology, Leibniz Institute for Neurobiology, Magdeburg, Germany, ${ }^{2}$ Wellcome Trust Centre for Neuroimaging, Institute of Neurology, University College London, London, UK, ${ }^{3}$ Ageing Research Centre, Karolinska Institute, Stockholm, Sweden, ${ }^{4}$ Institute of Human Genetics, Otto von Guericke University, Magdeburg, Germany, ${ }^{5}$ Institute of Cognitive Neurology and Dementia Research, Otto von Guericke University, Magdeburg, Germany, ${ }^{6}$ Institute of Cognitive Neuroscience, University College London, London, UK, ${ }^{7}$ German Center for Neurodegenerative Diseases, Magdeburg, Germany, ${ }^{8}$ Center for Behavioral Brain Sciences, Otto von Guericke University of Magdeburg, Magdeburg, Germany, ${ }^{9}$ Department of Psychiatry, Charité University Hospital, Berlin, Germany, ${ }^{10}$ Department of Neurology, Otto von Guericke University, Magdeburg, Germany
\end{abstract}

Daniela Laricchiuta IRCCS Santa Lucia Foundation, Italy

Keywords: dopamine D2 receptor, TaqIA, reward learning, motivated learning, action bias

Reviewed by:

Carlo Lai,

Sapienza University, Italy

*Correspondence: Anni Richter, anni.richter@lin-magdeburg.de

${ }^{\dagger}$ Present Address: Marieke Klein Department of Human Genetics, Donders Institute for Brain

Cognition and Behaviour, Radboud University Medical Centre, Nijmegen, Netherlands

Received: 20 January 2015 Accepted: 19 February 2015

Published: 11 March 2015

Citation:

Richter A, Guitart-Masip M, Barman A, Libeau C, Behnisch G, Czerney S,

Schanze D, Assmann A, Klein M, Düzel E, Zenker M, Seidenbecher $C$ and Schott BH (2015) Corrigendum: Valenced action/inhibition learning in humans is modulated by a genetic variant linked to dopamine D2 receptor expression.

Front. Syst. Neurosci. 9:36. doi: 10.3389/fnsys.2015.00036

\section{A Corrigendum on}

Valenced action/inhibition learning in humans is modulated by a genetic variant linked to dopamine $\mathrm{D} 2$ receptor expression

by Richter, A., Guitart-Masip, M., Barman, A., Libeau, C., Behnisch, G., Czerney, S., et al. (2014). Front. Syst. Neurosci. 8:140. doi: 10.3389/fnsys.2014.00140

We observed some errors that occurred during the genotyping of DARPP-32 rs907094. Naming of CC and TT homozygotes was swapped, and, furthermore, six genotypes were wrongly identified (three people changed from CT to CC, two people changed from CT to TT, and one person changed from TT to CT). All statistics that included DARPP-32 rs907094 genotype were recomputed. We have corrected the text in the corresponding text passages of the manuscript accordingly (last paragraph of the Results Section and Table 2). Importantly, these corrections did not affect our main findings, the effects attributable to the DRD2 TaqIA polymorphism.

Find below the last paragraph of the Results Section and Table 2 with the corrected statistics including DARPP-32 rs907094 genotype.

Corrected version of the last paragraph of the Results Section

Because the TaqIA polymorphism is located downstream of the DRD2 gene, the observed genotype effects might putatively result from linkage disequilibrium with other DRD2 polymorphisms, including the C957T. We indeed observed an imbalanced distribution of the C957T polymorphism (rs6277) among TaqIA A1 carriers vs. A2 homozygotes numerically in the first cohort $\left(\chi^{2}=4.04\right.$, $p=0.132)$ and significantly in the second cohort $\left(\chi^{2}=25.49, p<0.001\right)$. Moreover, the DARPP32 polymorphism (rs907094) was unequally distributed in the second cohort only $\left(\chi^{2}=7.62, p=\right.$ 0.022 ). In order to rule out confounding effects, we included the polymorphisms as covariates in an additional ANCOVA. The same was done for COMT Val108/158Met (rs4680), because the cohorts 


\section{Corrected version of Table 2.}

TABLE 2 | Demographic data.

A1+ A1-

\begin{tabular}{|c|c|c|c|}
\hline \multicolumn{4}{|l|}{ COHORT 1} \\
\hline Women/Men $(n=87)$ & $17 / 20$ & $26 / 24$ & $\chi^{2}=0.31, p=0.577$ \\
\hline Mean age $(n=87)$ & $24.9 \pm 3.6$ & $24.3 \pm 2.6$ & $t_{(85)}=0.83, p=0.410$ \\
\hline $\mathrm{COMT} \mathrm{mm} / \mathrm{vm} / \mathrm{vv}(n=87)$ & $13 / 14 / 10$ & $18 / 15 / 17$ & $\chi^{2}=0.73, p=0.694$ \\
\hline DAT1-VNTR $9+/ 9-(n=85)$ & $11 / 25$ & $15 / 34$ & $\chi^{2}<0.01, p=0.996$ \\
\hline C957T CC/CT/TT $(n=87)$ & $11 / 19 / 7$ & $8 / 24 / 18$ & $\chi^{2}=4.04, p=0.132$ \\
\hline \multicolumn{4}{|l|}{ COHORT 2} \\
\hline Women/Men $(n=95)$ & $13 / 21$ & $35 / 26$ & $\chi^{2}=3.20, p=0.074$ \\
\hline Mean age $(n=95)$ & $25.2 \pm 3.3$ & $24.2 \pm 2.4$ & $t_{(93)}=1.58, p=0.121$ \\
\hline Smokers/Nonsmokers $(n=95)$ & $5 / 29$ & $14 / 47$ & $\chi^{2}=0.93, p=0.335$ \\
\hline $\mathrm{COMT} \mathrm{mm} / \mathrm{vm} / \mathrm{vv}(n=95)$ & $11 / 14 / 9$ & 19/27/15 & $\chi^{2}=0.09, p=0.957$ \\
\hline DAT1-VNTR $9+/ 9-(n=93)$ & $17 / 17$ & $32 / 27$ & $\chi^{2}=0.16, p=0.693$ \\
\hline
\end{tabular}

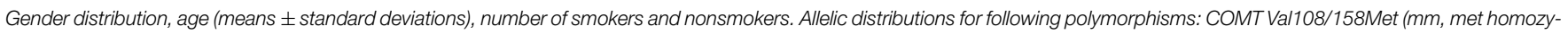

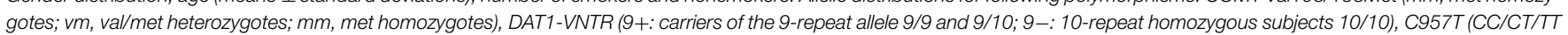
carriers), and DARPP-32 (CC/CT/TT carriers). A1+, carriers of the A1 allele; A1-, A2 homozygotes.

were stratified with respect to that polymorphism. Importantly, the fourfold action by valence by time by genotype interaction for the TaqIA polymorphism remained significant [cohort 1: $F_{(1,82)}=4.67, p=0.034$, cohort $\left.2: F_{(1,90)}=4.65, p=0.034\right]$, while there was no effect for C957T (cohort 1: $p=0.484$, cohort 2: $p=0.832$ ), DARPP-32 (cohort $1: p=0.610$, cohort 2: $p=0.235$ ), or COMT Val108/158Met polymorphism (cohort 1: $p=0.149$, cohort $2: p=0.842$ ).

\section{Acknowledgments}

The authors would like to thank Iris Mann for help with testing and Maria Michelmann for help with genotyping. This project was supported by the Deutsche Forschungsgemeinschaft (SFB 779, TP A07 and A08) and the Leibniz Graduate School (PhD stipend to $\mathrm{AB}$, Master stipend to MK).

Conflict of Interest Statement: The authors declare that the research was conducted in the absence of any commercial or financial relationships that could be construed as a potential conflict of interest.

Copyright (ㅇ 2015 Richter, Guitart-Masip, Barman, Libeau, Behnisch, Czerney, Schanze, Assmann, Klein, Düzel, Zenker, Seidenbecher and Schott. This is an openaccess article distributed under the terms of the Creative Commons Attribution License (CC BY). The use, distribution or reproduction in other forums is permitted, provided the original author(s) or licensor are credited and that the original publication in this journal is cited, in accordance with accepted academic practice. No use, distribution or reproduction is permitted which does not comply with these terms. 